This is a postprint version of the following published document:

Agzenai , Y., Pozuelo, J., Sanz, J., Pérez, I. y Baselga, J. (2015): Advanced Self-Healing Asphalt Composites in the Pavement Performance Field: Mechanisms at the Nano Level and New Repairing Methodologies. Recent Patents on Nanotechnology, 9 (1), pp. 43-50.

(C) Bentham Science Publishers, 2015 


\title{
Advanced Self-Healing Asphalt Composites in the Pavement Performance Field: Mechanisms at the Nano Level and New Repairing Methodologies
}

\author{
Yahya Agzenai ${ }^{1}$, Javier Pozuelo ${ }^{1}$, Javier Sanz ${ }^{2}$, Ignacio Pérez ${ }^{3}$ and Juan Baselga ${ }^{1 *}$
}

\begin{abstract}
In an effort to give a global view of this field of research, in this mini-review we highlight the most recent publications and patents focusing on modified asphalt pavements that contain certain reinforcing nanoparticles which impart desirable thermal, electrical and mechanical properties. In response to the increasing cost of asphalt binder and road maintenance, there is a need to look for alternative technologies and new asphalt composites, able to self-repair, for preserving and renewing the existing pavements. First, we will focus on the self-healing property of asphalt, the evidences that support that healing takes place immediately after the contact between the faces of a crack, and how the amount of healing can be measured in both the laboratory and the field. Next we review the hypothetical mechanisms of healing to understand the material behaviour and establish models to quantify the damage-healing process. Thereafter, we outline different technologies, nanotechnologies and methodologies used for self-healing paying particular attention to embedded micro-capsules, new nano-materials like carbon nanotubes and nano-fibres, ionomers, and microwave and induction heating processes.
\end{abstract}

Keywords: Asphalt pavements, induction heating, micro-capsules, microwave absorption, road engineering, self-healing, carbon nanotubes, graphite, silicon dioxide, titanium dioxide.

\section{INTRODUCTION}

Asphalt is a viscoelastic material produced through the refining of petroleum and widely used on paving roads and streets (more than $94 \%$ of pavements around the world are based on asphalt binder). It adheres to aggregate particles binding them in asphalt concrete. Ideally, asphalt must preserve its initial properties despite the daily traffic loads and the climate changes (especially temperature and moisture) for a prolonged period. However, after an in-service period of a few years, the flexibility and relaxation capacity of asphalt concrete decreases, the binder becomes brittle causing aggregate segregation, and an extensive damage appears on its surface. This ageing process begins at the hot mixing initial stage and continues throughout its service life due to heat, oxygen, and ultraviolet radiation (UV) exposure. That is the reason why asphalt concrete wearing courses should be regularly maintained and repaired [1].

It is well-known that asphalt has a self-healing capacity for repairing ageing damage which restores its functionality at least to some extent $[2,3]$. Its complex chemical composition contributes to healing, i.e. the aromatic components promote healing because of the $\pi$-stacking of the aromatic rings, or its amphoteric character associated to the heteroatom

\footnotetext{
*Address correspondence to this author at the Department of Materials Science \& Engineering (IAAB), Universidad Carlos III de Madrid, Av. Universidad 30, 28911 Leganés, Madrid, Spain; Tel: +34 9162494 67; Fax: +34 9162494 30; E-mail: jbaselga@ing.uc3m.es
}

content promotes healing through polar-polar bonds. Additionally, the wax content is also an important healing agent due to the van-der-Waals interactions between long chain aliphatic hydrocarbon molecules.

Healing, defined as the partial recovery of mechanical properties (i.e. strength and stiffness) during the rest period, can be understood as a diffusion process between the crack faces which erases the discontinuity of the material $[2,4,5]$. To quantify this process many factors should be considered such as type of the mixture, rest period and temperature. For instance, a soft asphalt binder shows a higher healing capacity than a hard asphalt binder; also, high asphalt content favours healing $[6,7]$ as well as long rest periods before loading [8], especially when the material is subjected to high temperatures [9].

In view of the self-healing property of asphalt and his temperature dependency it is reasonable to develop new thermal-based technologies and composite materials to repair pavement. Various schemes have been proposed and successfully applied at both, laboratory and filed scales. Here, we will focus on microwave heating, induction heating, ionomers and micro-encapsulation.

The overall objective of this mini-review is to examine an updated current state of knowledge on fatigue-healing in asphalt pavement. We will try to identify the principal mechanisms of self-healing in asphalt which are necessary to be considered in self-healing pavement design. Then we will

${ }^{1}$ Department of Materials Science \& Engineering (IAAB), Universidad Carlos III de Madrid, Av. Universidad 30, 28911 Leganés, Madrid, Spain; ${ }^{2}$ Department of Electrical Engineering, Universidad Carlos III de Madrid, Av. Universidad 30, 28911 Leganés, Madrid, Spain; ${ }^{3}$ Technical Department, 
summarize the investigations made during the last two

decades to repair old pavements, macro-cracks and potholes.

\section{SELF-HEALING}

Healing is a well-known phenomenon which occurs in materials and biological systems. It can be defined as the ability of a material to repair damages automatically and autonomously. To enhance this property sometimes an external trigger is necessary; in this work we focus on the nonautonomous self-healing process [10].

Although the healing capacity of different materials has been addressed in the literature, only a few papers report on asphalt self-healing. Suresh classified the healing mechanism, or fatigue crack growth delay, into five categories [11]: (i) Plasticity-induced: during crack propagation the material is plastically deformed at the crack tip; once the load is removed, residual stresses in the matrix induce micro-closures and reduce the theoretical opening of the crack front; (ii) Oxide-induced: deposit of debris oxide on freshly broken surfaces especially in humid conditions; the thickness of this oxide layer may be large enough to prevent total closure changing the propagation kinetics of the crack; (iii) Roughness-induced: the irregularities and the micro movements of the fracture surfaces prevent the total closure in absence of load; (iv) Viscous fluid-induced: a viscous fluid penetrates within a growing fatigue crack affecting its propagation rate; and finally, (v) Transformation-induced: phase transformations at the tip of the fatigue crack can delay the crack growth rate.

\subsection{Hypothetical Mechanisms}

Crack healing occurs immediately after removing the external load; at this time two phenomena take place: first the viscoelastic recovery in the bulk material, and second the healing in the cracked zone. The difference between both processes is that while the former is due to molecular rearrangement within the material, the latter is a consequence of wetting and inter-diffusion between the faces of the crack to reach the properties of the virgin material. Based on the pioneering work of Wool and O'Connor in polymer healing, the healing process is made of the following three stages:

i. Wetting of the two faces of a nano-crack.

ii. Interfacial cohesion between the crack faces.

iii. Diffusion and randomization of molecules from one face to the other to reach the properties of the virgin material.

By using the reputed model proposed by de Gennes to explain the movement of a polymer molecule in a worm like fashion inside a cross linked polymeric gel [12], Wool and O'Connor suggested a new approach to describe the healing by combining an intrinsic healing function of the material with a wetting distribution function using the following convolution integral [13]:

$$
R=\int_{\tau=-\alpha}^{\tau=t} R_{h}(t-\tau) \frac{d \emptyset(\tau, X)}{d \tau} d \tau
$$

where $R$ is the net macroscopic healing, $R_{h}(t)$ is the intrinsic healing function of the material, $\emptyset(t, X)$ is the wetting distribution function, and $\tau$ is the time variable.

The wetting distribution function, $\varnothing(t, X)$, defines wetting at the contact of the two cracked surfaces in a domain $X$ over time $t$. For analytical purposes, the wetting function can be simplified by considering that wetting occurs at a constant rate and this rate is dictated by the mechanical, and the viscoelastic properties of the asphalt material. For example, asphalt with higher surface free energy will have stronger intermolecular forces of attraction between the two cracked surfaces and will therefore wet at a faster rate. Based on the quasi-static analysis of cohesive fracture of linear viscoelastic media, Schapery developed an equation that relates the work of cohesion and the material properties (Poisson coefficient and creep compliance parameters) with the wetting of the crack surfaces. Thus, the rate of wetting of a crack surface is given by [14]:

$$
\frac{d \varnothing(t, X)}{d t}=\dot{a}_{b}=\beta\left[\frac{1}{D_{1} k_{m}}\left(\frac{\pi W_{c}}{4\left(1-v^{2}\right) \sigma_{b}^{2} \beta}-D_{0}\right)\right]^{\frac{-1}{m}}
$$

where, $W_{c}$ is the work of cohesion; $v$ is the Poisson coefficient; $D_{0}, D_{1}$, and $m$ are the creep compliance parameters obtained from the generalized Andrade creep function $D(t)=D_{0}+D_{1} t^{m}$; and $k_{m}$ is a material constant that can be calculated from $m$. The meaning of $\sigma_{b}, \beta$, and $\dot{a}_{b}$ is illustrated in Fig. (1).

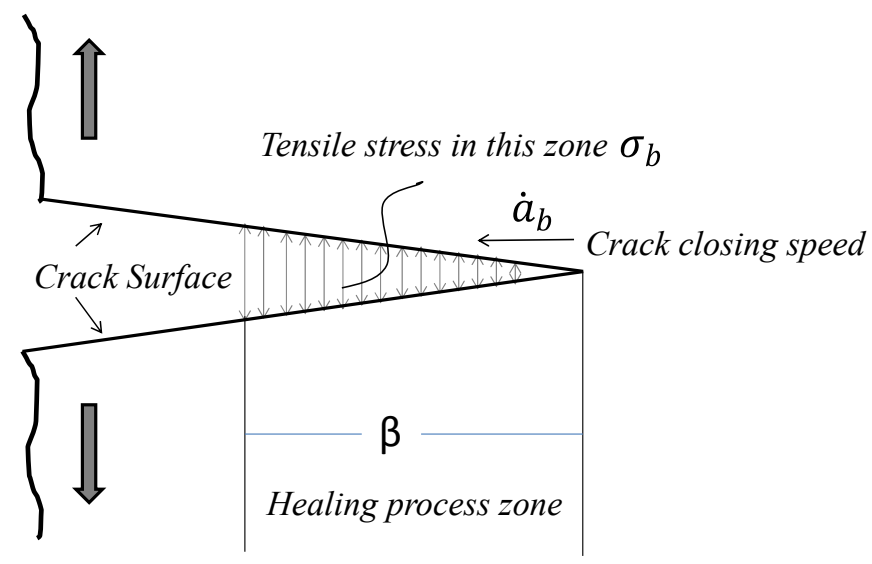

Fig (1). Crack propagation and fracture process/healing zone in mode I loading (adapted from Little et al. [2]).

The next steps of the healing asphalt process (i.e. the strength gain caused by interfacial cohesion and diffusion of molecules between crack faces) are described by the intrinsic healing function $R_{h}(t)$. Little et al. [15]. proposed a modified form of the Avrami equation, equation (3), which is commonly used to describe processes such as kinetics of phase transformations in solids and chemical reaction rates.

$$
R_{h}(t)=R_{0}+p\left(1-e^{-q t^{r}}\right)
$$

Where, $p, q$, and $r$, are material-related parameters that define the time-dependent strength gain at the interface. This equation introduces a constant, $R_{0}$, which represents the in- 
stantaneous strength gain across wetted crack surfaces as a result of their interfacial work of cohesion, and a second term, which is a time-dependent strength gain caused by inter-diffusion of the molecules between crack faces.

Among other attempts, Darabi et al. [16] suggested a continuum damage mechanics framework to model asphalt healing, in line with Palvadi et al. [17] who proposed another model to quantify healing in asphalt composites. Hou et al., [18] based on a phase field model, simulated the self-healing mechanism of asphalt from mechanical and thermodynamic arguments; they realized that the reduction of surface free energy originates the gradual disappearance of the initial cracks as temperature increases. Considering self-healing as a diffusive process, molecular dynamic simulations can also be employed to investigate the internal mechanism. A remarkable review was published recently by Greenfield regarding bituminous materials [19].

\subsection{Methods to Quantify Asphalt Concrete Self-Healing}

As the healing process in pavements is usually related to micro cracking and fatigue damage, the most common way to quantify it involves the use of diverse fatigue tests carried out with different rest periods allowing asphalt to heal. Different approaches have been successfully used to quantify the magnitude of healing in different asphalt binders, mastics, or mixtures.

(i) Although there is a lack on a widely accepted test to measure the fatigue performance of asphalt binders, the use of Dynamic Shear Rheometer (DSR) for evaluating damage behaviour under continuous oscillatory shear stress (fatigue tests) and damage recovery after load removal (healing tests) has been reported by different authors like Lu et al. [20], Qiu et al. [21] and Santagata et al. [22] Different parameters like Relative Dissipated Energy ratio (DER), Crack Propagation Amplitude (RCPA) and Relative Healing Index (RHI) have been described to quantify the fatigue behaviour of the asphalt binders.

(ii) Shen et al. [23] use the Four-Point Bending Beam Test and the Ratio of Dissipated Energy Change (RDEC) approach to evaluate the fatigue behaviours of different asphalt mixes. During a cyclic fatigue test, the stress-strain hysteresis loops do not overlap. The area inside this loop indicates the amount of dissipated energy in the form of mechanical work, heat generation, or damage. RDEC is defined as the ratio of dissipated energy change between two consecutive loading cycles and is given by:

$R D E C=\frac{D E_{n+1}-D E_{n}}{D E_{n}}$

Fig. (2) illustrates the three stages in which the damage curve represented by RDEC vs. loading cycles can be divided. After an initial loading period (step I) the damage curve develops a plateau. During this plateau step (step II) there is a relatively constant percentage of input energy being turned into damage. This step extends all over the main service life until a dramatic increase in RDEC appears which gives a sign of true fatigue failure (step III).

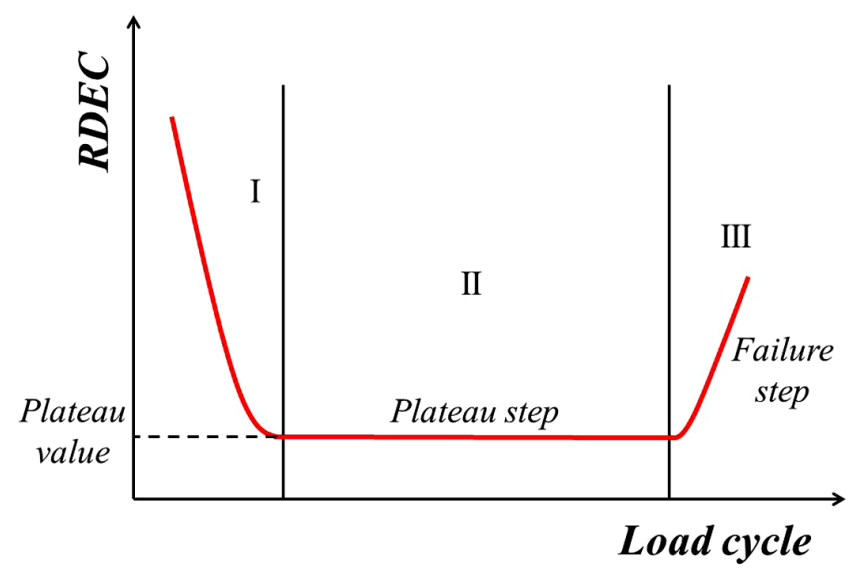

Fig. (2). Typical RDEC plot with three behavior steps. (Adapted from Carpenter et al. [24]).

(iii) Ultrasonic waves. Films of asphalt binder held between two protuberances (glass or steel) simulating two aggregates in the asphalt mix, are submitted to cyclic loadings in both tension and compression; the rate of healing in the asphalt film is quantified by ultrasonic wave transmission. When the signal amplitude decreases it reflects film damage while if it increases healing process may take place [25]. More advanced techniques using neural networks for ultrasonic detection can evaluate more quickly and effectively the damage state of asphalt mixture [26].

(iv) Dynamic mechanical analysis (DMA) is another technique used to measure the fatigue characteristics of asphalt mixtures (only asphalt binder with fine aggregates). The DMA is an efficient tool to perform dynamic analysis of asphalt mixtures under controlled-strain: tension, compression and torsion. There are two methods to evaluate the fatigue life of the asphalt mixtures using this technique: (a) the loss of the normalized dynamic modulus, and (b) the rate of change of dissipated energy which is the amount of energy dissipated in each load cycle due to the damage of the specimen. A deep theoretical background of this technique and the methodology used to perform measurements are reported in the work of Kim et al. [27].

\section{NOVEL TECHNOLOGIES IN NON-AUTONOMOUS SELF-HEALING}

Pavement repair and rehabilitation is handled in many ways, ranging from sealing or filling cracks, to resurfacing, which is both uneconomical and technically unsound. The challenges are to increase the lifetime of the asphalt pavements, to make the pavements apt for an immediate and local repair of the generated damage without stop traffic circulation and to recycle the old pavements.

As it has been already mentioned, the healing rate of asphalt increases with temperature; for this reason, the addition of conductive additives that may improve its thermal and electrical conductivity and the use of adequate devices to locally heat the pavement have been proposed to heal the cracks and repair the pavement. Based on the temperature effect two main techniques are used: 


\subsection{Microwave Heating}

Some of the characteristic keys of microwave interaction with materials are: i) penetrating radiation, ii) controllable electric-field distribution, iii) rapid heating, vi) selective heating, and v) self-limiting reactions [28]. The two main mechanisms of heating for non-magnetic materials are conduction losses (dominant in metallic and high conductivity materials) and dipolar (dielectric) losses (dominant process for dielectric insulators). Magnetic materials also exhibit conduction losses with additional magnetic losses such as hysteresis, domain wall resonance and electron spin resonance. In general, the lossy microwave absorptive material comprises a material selected from the group consisting of semi-conductors, ferromagnetic materials, metal oxides, dielectric materials, metals (in powder or particle form) and mixtures thereof.

\subsection{Induction Heating}

Induction heating is a technique already used to repair or remove asphalt pavements [29, 30]. It allows very local and extremely fast heating within the material. It is based on the well-known electromagnetic induction phenomenon and applied to pavements doped with ferromagnetic conducting materials such as steel wires. When a magnetically susceptible and electrically conducting material is located within the magnetic field generated by an external alternating current, an eddy current is induced in the material which causes its heating by the Joule effect. A simple model for heating asphalt composites has been proposed by Garcia et al. [31], and the main concepts and applications can be found elsewhere $[32,33]$.

A material able to be healed by induction heating method should satisfy two main requirements: i) it must be conductive, which can be achieved by adding electrically conductive fillers or fibres to the asphalt mixtures; ii) these additives must be connected in closed-loop circuits (Fig. 3). According to Ahmed et al. the heating of doped asphalt can be explained by various mechanisms such as dielectric hysteresis heating and contact resistance heating, but the predominant one is the fibre heating [34].

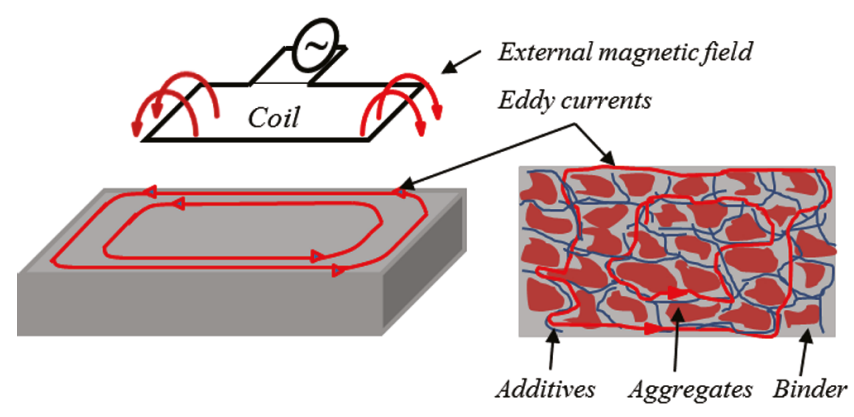

Fig. (3). Induction heating scheme.

\subsection{Microencapsulation}

In this approach the objective is not, as in the former ones, to just repair the pavement but to rejuvenate the asphalt binder and so the mix and the pavement. It is well-known, that the healing property of pavements decreases drastically when asphalt is aged. To avoid this, first attempts were based on the use of maltenes, the liquid phase of asphalt, on damaged pavement, but this type of treatment remains superficial. Current alternatives use microcapsules filled with selfhealing components that are dispersed in the asphalt mixture. In this approach, healing agents, usually viscous hydrocarbons, are encapsulated and embedded within the asphalt concrete. Fig. (4) shows a scheme of the healing process by microencapsulation; once the crack reaches the microcapsules they break and release the healing agents. Diffusion of both, the healing agents and the damaged asphalt induce closing the cracks and healing of the asphalt concrete.

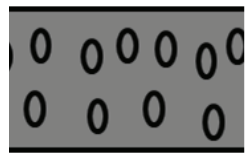

(a)

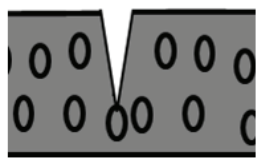

(b)

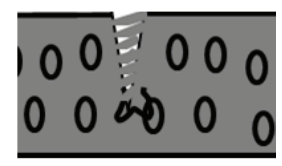

(c)
Fig. (4). Mechanism of microencapsulation (a) new pavement with microcapsules (b) crack reaches a microcapsule (c) microcapsule breaks and releases the healing agent.

However, although the concept appears to be simple, the challenge remains in the design of this kind of healing materials. Core-shell technology could be a convenient means provided that the following requirements are fulfilled: i) the core should have a good compatibility with asphalt binder, ii) the shell should not react with it, iii) both core and shell should be able to resist the high temperatures and stresses during the mixing and the compaction processes of asphalt concrete, although they should not be so resistant so that they never break; besides, the size should fit in the micron range [35] to facilitate the mixing process (nevertheless some papers [36] report the use of capsules up to $2 \mathrm{~mm}$ ), and the healing temperature should be in the range $-30{ }^{\circ} \mathrm{C}$ to $70{ }^{\circ} \mathrm{C}$.

\subsection{Ionomers}

Another technique used to improve the self-healing property of asphalt is the use of ionomers: ${ }^{2}$ a class of thermoplastic copolymers containing a fraction of ionic groups in their backbone (up to 20\%). These latter interact and form partially cross-linked clusters which affect the overall mechanical and viscoelastic properties of the material. The healing in systems involving ionomers has been studied using ballistic tests and, in general, its mechanism has been attributed to the shape of projectile, temperature and the ionic content. This technique is the least expensive, and ensures up to $70 \%$ of recovery in a very short period of time.

Table 1 recapitulates some benefits and drawbacks of the techniques summarised above [37-39]:

\section{ADVANCED SELF-HEALING ASPHALT MIX- TURES}

One of the most effective methods to reinstate the asphalt original properties is the use of encapsulated rejuvenators inside the asphalt to restore the asphaltene/maltene ratio. 
Table 1. Benefits and drawbacks of asphalt self-healing techniques.

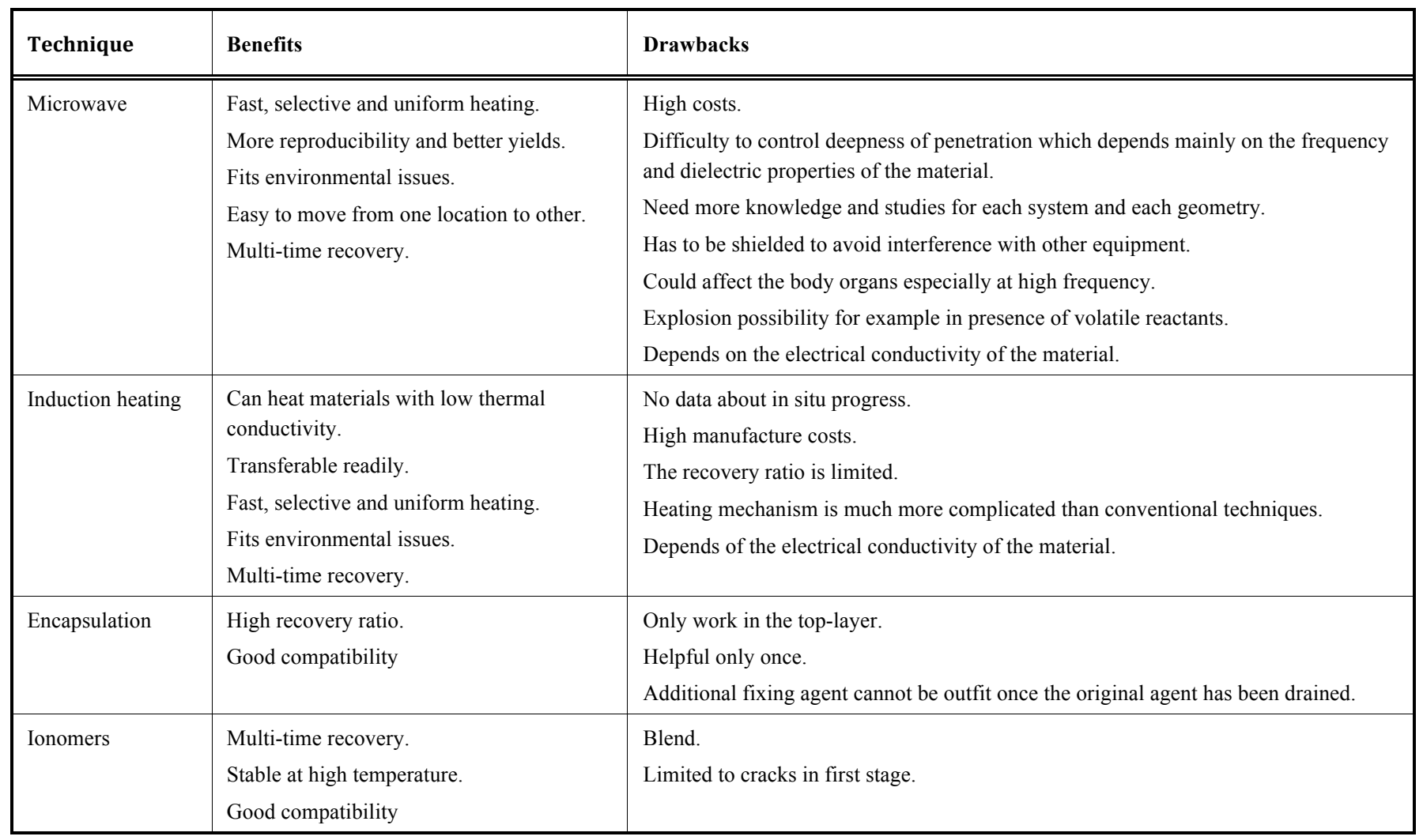

Rejuvenator materials consist of lubricating and extender oils, which contain a high proportion of maltene constituents. $\mathrm{Su}$ et al. reported the synthesis of novel microcapsules in which the rejuvenator core had been encapsulated by a hard shell, which was fabricated by in-situ polymerization of methanol-melamine-formaldehyde (MMF) pre-polymer. The mechanism of this method was a two-step coacervation with the aid of styrene maleic anhydride as a nonionic dispersant. The compact shell structure obtained with this method made the microcapsules able to resist the melting temperature of asphalt [40, 41].

Several proposals to prepare advanced asphalt composites susceptible to microwave heating in an efficient manner are reported in the literature. Jeppson, was the first to use microwave energy for heating and reconditioning of an asphalt pavement. In his US patent No. 4,319,856 he describes a large variability in the ability of asphalt to be heated by microwave energy and he attributes most of the heating to silicate rocks absorbing the microwave energy in varying degrees [42]. To solve this, he used a sheet of microwave reflective material such as a metal foil to be applied below the road surfaces to concentrate the microwave energy in the top layer of asphalt material. This was achieved reflecting the microwave energy from the metal foil layer [43].

Following the same concept, Long et al., proposed in a series of patents the use of a three-layer sheet on top of the concrete: a reflective layer, a heat insulator layer and a graphite containing epoxy top layer. Although this technique reaches his objective it remains very expensive. To reduce the variability in microwave heating, Long et al. considered another procedure employing anthracite coal. It is an excellent lossy microwave absorbing material due to its high carbon content that may be added to the asphaltic mixture in the range $10-30 \mathrm{wt} \%$. Other reason for the use of anthracite is its hydrophobicity, which makes it chemically stable and weather resistant. These asphaltic concrete compounds facilitate the penetration of heat, which in turn debond ice from the concrete and create strong bonds throughout the repaired pavement [44-46].

Further and importantly, for keeping uniform temperature of the asphalt materials exposed to microwave radiation, Hutcheson et al., [47] used another reinforcing candidate, ferrite powder, a ferromagnetic material, with Curie temperature between 100 and $125^{\circ} \mathrm{C}$ and high volume resistivity. Compared to metals, ferrite powders are preferred as they do not oxidize during heating although they appreciably enhance the heating of asphalt only up to the Curie temperature. Thereafter, further radiation will not be effective and heating will be relatively insignificant due to the high volume resistivity. This approach was very useful reducing significantly the required time to melt asphalt with only 2 to 5 wt.\%. The advantage of ferrites as good lossy microwave materials was confirmed by Bowen et al. in their US patent No. 5092,706; they provide a new methodology for repairing a void such as a pothole in asphalt pavement, mixing ferrites in the tack used for the tack layer and then applying microwave energy to heat the tack which forms a strong interface bond between the asphalt patch and the inner surface of the pothole [48]. 
Regarding induction heating, García et al. attempted to make conductive asphalt mastic by addition of steel wool fibres, and used induction heating to heat the mastic enhancing its self-healing properties [31]. The results suggested the existence of a limiting volume fraction of fibres at which all the fibres were surrounded by asphalt binder; above this value temperature don't increase anymore appearing clusters in the medium susceptible to oxidation and loss of properties. Furthermore, this value was coincident with the quantity needed to reach the maximum conductivity of the mastic, below this optimum volume fraction the mastic behaves as a non-conductive material, although the heating effect still exist as a result of local conductivity [49]. To find the optimum fibre content Garcia et al. used the percolation theory, i.e. the volume of conductive additives was progressively increased and each mixture was analysed separately until the resistivity dropped suddenly to a second plateau [50]. It was proved that the use of induction heating didn't damaged the mastic and the number of times that a pavement could be healed was dependent on the maximum temperature reached. Furthermore, sand-bitumen ratio was a key factor in the design of conductive asphalt mixtures and it couldn't be considered separately from the amount of conductive particles. To increase the sand-bitumen ratio, they added graphite [50].

The use of other forms of carbon and their effects on asphalt properties has also been explored by other groups. Wen et al. pursued to increase the softening point of asphalt by addition of carbon black. They achieved a notable increase from 40.1 to $80.9{ }^{\circ} \mathrm{C}$ upon addition of 7 vol.\% of carbon black in combination with sand. At the same time the addition of carbon black decreased the electrical resistivity of the asphalt, especially when the carbon black volume fraction exceeded the percolation threshold [51].

A comparative study of three additives: carbon fibres, graphite and carbon black were reported by $\mathrm{Wu}$ et al. Their results showed that conductive carbon fibres were much more effective than conductive fillers (graphite or carbon black) to increase the conductivity of the asphalt mixtures, but it was very difficult to prepare well dispersed mixtures because fibres form cluster aggregates in the mixture. In addition, a remarkable enhancement of conductivity was detected using a combination of two or more fillers [52] that could be explained in terms of two kinds of contacts: short range contacts within the clusters and long range contacts due to the bridging effect of fibres [52-54].

The decrease of the characteristic length of conductive fillers for asphalts down to the nanoscale is a challenging issue. The main envisaged benefit is concerned with the skin depth when using high frequency radiation for heating. In the microwave range, skin depth may be as small as tens of nanometers so the majority of the filler may be inactive against radiation if its size is in the micron range or higher.

A limited number of works have been reported to date with nanofillers. Pang et al. reported bitumen modified with inorganic nanomaterials prepared from carbon nanotubes, nano-ceria and coal tar, which had good high and low temperature performance and anti-aging properties [55]. Goldin et al. also used carbon nanotubes dispersed in bitumen along with technical carbon and organoclay to produce an organicbased asphalt concrete apt to be utilized to make road surfac- es [56]. Sun et al. employed carbon nanotubes to improve the compatibility of SBS rubber and asphalt. When the SBS absorbs the carbon nanotubes, the SBS becomes more evenly distributed in the asphalt matrix resulting in a more stable composite with better performance [57]. The effects of SBS on the properties of modified asphalt mixtures have also been studied in the presence of nano- $\mathrm{SiO}_{2}$. The results of workability tests (Marshall Stability, indirect tensile strength, tensile strength ratio and indirect tensile stiffness modulus) indicated that the mixtures with $5 \%$ SBS and $2 \%$ nano- $\mathrm{SiO}_{2}$ had the most improved mechanical behaviour [58].

Hao et al., mixed nano calcium carbonate into asphalt. Data showed that the mixing of $6 \%$ of these inorganic nanoparticles improved both the high temperature performance and water stability of asphalt concrete [59]. Nanoclay particles also modify and improve the rheological characteristics and the rutting resistance of bitumens and asphalt composites. However, fatigue performance decreases at low temperatures $[60,61]$.

Tanzadeh et al. carried out wheel-tracking test on ordinary and nano- $\mathrm{TiO}_{2}$ modified hot mix asphalt samples. The results of their study showed that the use of nano- $\mathrm{TiO}_{2}$ in asphalt binder samples improves rutting resistance in asphalt pavement under dynamic loading in comparison with the ordinary mixtures [62]. Shafabakhsh et al., also investigated the effect of nano- $\mathrm{TiO}_{2}$ in asphalt mixtures. They found that replacing $5 \%$ of bitumen by nano- $\mathrm{TiO}_{2}$ the creep behaviour of asphalt mixture even at high temperature was improved. Nano- $\mathrm{TiO}_{2}$ prevents tensile cracks from being easily generated by horizontal tensile stresses [63].

Qiu et al., conducted self-healing tests to study the effect of nanoparticles (full vulcanized rubber nanopowders) into asphalt binder. Preliminary results indicated that the shear modulus recovery (1.5 hours) occurred faster than strength recovery ( 6 hours). It could be concluded that these nanoparticles improved the self-healing capacity of asphalt binder and, thus, the service life. However, it is important to take the different test temperatures into account before drawing general conclusions since vulcanized rubber is insoluble in asphalt [64].

Only a few studies have been conducted using ionomers; in most cases they were employed in polymeric systems whether to control morphology, modify physical properties and/or to enhance self-healing behaviour. For instance, Varley and Zwaag reported a comparative work between Surlyn 8940 ionomer and a non-ionic polymer with similar backbone: linear low-density polyethylene LLDPE. Results show that the healing rate under ballistic impact depends mainly on the presence of ionic clusters [65]. Regarding application on paving materials, an European patent EP0548412 A1 published by Luc and al. report the use of ionomers in a bituminous material; the resulting systems were able to resist to flow at high temperature (up to $210{ }^{\circ} \mathrm{C}$ ) [66]. US Pat. No. 4839404 describes new bituminous materials with more adherence to aggregates, based on $\alpha, \beta$ ethylenically unsaturated carboxylic acid ionomer and any kind of bitumen. Although the patent provides the manufacture method, no characterization of the mechanical, rheological or thermal properties of the resulting products is given [67]. Shi Ying studied asphalt/copolymers of ethylene and methacrylic acid 
ionomer systems; the latter gave more homogeneous mixtures compared to polyethylene modified asphalt and improved elasticity at low temperature; however, to obtain good blends remains very sensitive to the mixing time and the ionic proportions [68].

Although the addition of nanoparticles seems to improve mechanical and rheological properties of asphalt mixtures prevent cracks growth and increase service life of pavements- the main disadvantage remains in obtaining good dispersions in the asphalt matrix, which is even more challenging in the presence of aggregates. There is no standard procedure to obtain good dispersions so detailed investigations should be carried out to determine the most adequate methodology.

Furthermore, one should keep in mind that the repair capacity should not only be effective under laboratory conditions. A relevant system should resist the harsh conditions during mixing, compaction as well as those during service life and should be active at temperature ranging from $-30{ }^{\circ} \mathrm{C}$ to $70{ }^{\circ} \mathrm{C}$.

\section{CURRENT \& FUTURE DEVELOPMENTS}

The above mentioned technologies represent a revolution in the road construction and maintenance, they are successfully employed in field, and it is expected that they will double the lifetime of the new pavements reducing the maintenance costs. Microwaves and induction heating promote local and fast heating inside the material which increases the healing rates of bitumen; this is done by dispersing microwave absorbing materials and conductive additives in asphalt matrix. Micro-encapsulation repairs damage by decreasing the stiffness of pavement and closing the cracks, increasing, therefore its durability.

Nevertheless, several challenges still need to be addressed. Among others: obtaining good dispersions of additives in the asphalt binder and asphalt concrete, which should ensure homogeneous properties, and design of nanocapsules able to resist the high temperature and pressure during the mixing and compaction processes. Furthermore, they are various models to quantify binder (asphalt) healing but it is still needed more effort to model this process in asphalt composites.

\section{CONFLICT OF INTEREST}

The authors confirm that this article content has no conflict of interest.

\section{ACKNOWLEDGEMENTS}

Authors wish to thank Spanish Ministerio de Ciencia e Innovación for grants IPT-2011-1359-420000 and MAT201017091.

\section{REFERENCES}

[1] Yu JY, Feng PC, Zhang HL, Wu SP. Effect of organomontmorillonite on aging properties of asphalt. Constr Build Mater 2009; 23: 2636-40.

[2] Little DN, Bhasin A. In: Zwaag S. Ed. Self healing materials. Dor-drecht: Springer 2007: pp. 205-18.
[3] Daniel J, Kim Y. Laboratory evaluation of fatigue damage and healing of asphalt mixtures. J Mater Civ Eng 2001; 13: 434-40.

[4] Kim YR, Lee H, Little DN. Microdamage healing in asphalt and asphalt concrete. Vol. IV: a viscoelastic continuum damage fatigue model of asphalt concrete with microdamage healing. Texas : Tex-as Transportation Institute, College Station 2001.

[5] Bonnaure FP, Huibers AH, Boonders A. A laboratory investigation of the influence of rest periods on the fatigue characteristics of bi-tuminous mixes. Association of Asphalt Paving Technologists -Annual Meeting, Kansas City, USA 1982.

[6] Van Gooswiligen G, Hilster E, Robertus C. Changing Needs and Requirements for Bitumen and Asphalts Proceedings of the $6^{\text {th }}$ conference
on Asphalt Pavements, Cape Town, Southern Africa, October 1994.

[7] Molenaar AAA. Prediction of fatigue cracking in asphalt pavements. Transport Res Rec 2007; 2001: 155-62.

[8] Kim YR, Little DN, Lytton RL. Fatigue and healing characterization of asphalt mixes. J Mater Civil Eng 2003; 15: 75-83.

[9] Liu Q, Schlangen E, Van de Ven M. Evaluation of the induction healing effect of porous asphalt concrete through four-point bending fatigue test. Constr Build Mater 2012; 29: 403-9.

[10] Ghosh SK. In: Ghosh SK. Ed. Self-Healing Materials: Fundamentals, Design Strategies, and Applications. Weinheim: Wiley-VCH, 2009: pp. 1-28.

[11] Suresh S. Fatigue of materials. 2nd Ed. Cambridge: Cambridge University Press 1998.

[12] De Gennes PG. Reptation of a polymer chain in the presence of fixed obstacles. J Chem Phys 1971; 55 (2): 572-9.

[13] Wool RP, O'Connor KM. A theory of crack healing in polymers. J Appl Phys 1981; 52: 5953-63.

[14] Schapery RA. On the mechanics of crack closing and bonding in linear viscoelastic media. Int J Fracture 1989; 39: 163-89.

[15] Bommavaran RR, Bhasin A, Little DN. Determining intrinsic healing properties of asphalt binders. Transport Res Rec 2009; 2126: 47-54.

[16] Darabi M, Abu Al-Rub R, Little DN. A continuum damage mechanics framework for modeling micro-damage healing. Int J Sol-ids Struct 2012; 49: 492-513.

[17] Palvadi S, Bhasin A, Little DN. Method to quantify healing in asphalt composites by continuum damage approach. Transport Res Rec 2012; 2296: 86-96.

[18] Hou Y, Wang L, Pauli T, Sun W. An Investigation of asphalt selfhealing mechanism using phase-field model. J Mat Civil Eng 2014; (doi: 10.1061/(ASCE)MT.1943-5533.0001047).

[19] Greenfield ML. Molecular modelling and simulation of asphaltenes and bituminous materials. Int J Pavement Eng 2011; 12: 325-41.

[20] Lu X, Soenen H, Redelius P. Fatigue and healing characteristics of bitumens studied using dynamic shear rheometer Proceeding of the $6^{\text {th }}$ 2003.

[21] Liu Q, Garcia A, Schlangen E, Van de Ven M. Introduction healing of asphalt mastic and porous asphalt concrete. Constr Build Mater 2011; 25: 3746-52.

[22] Santagata E, Baglieri O, Dalmazzo D, Tsantilis L. Damage and healing test protocols for the evaluation of bituminous binders. Proceeding of the $3^{\text {th }}$ Euroasphalt and Eurobitume Congress, Is-tanbul, Turkey, June

[23] Shen S, Carpenter SH. Dissipated energy concepts for HMA Performance: Fatigue and healing. COE Report No.29, Technical Re-port of Research, University of Illinois at Urbana-Champaign, Urbana, USA, 2007.

[24] Carpenter SH, Ghuzlan KA, Shen S. A fatigue endurance limit for highway and airport pavement. Transport Res Rec 2003; 1832 131-8.

[25] Maillard S, de La Roche C, Hammoum F, Gaillet L, Such C. Experimental investigation of fracture and healing at pseudo-contact of two

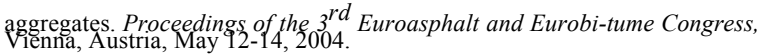

[26] Cheng Y, Zhang P, Jiao Y, Wang Y, Tao J. Damage simulation and ultrasonic detection of asphalt mixture under the coupling effects of water-temperature-radiation. Adv Mat Sci Eng 2013; 2013: 1-9.

[27] Kim YR, Little DN, Lytton RL. Fatigue and healing characterization of asphalt mixtures. J Mater Civ Eng 2003; 15: 75-83.

[28] Committee on Microwave Processing of materials: An emerging industrial technology, commission on engineering and technical 
systems, national research council. Microwave processing of mate-

rials. Washington DC: National Academy Press 1994.

[29] Koji S, Masuo I, Masanobu C. Induction heating equipment for bridge deck asphalt pavement. JP2007146459, 2007.

[30] Harakawa K, Hayashida H, Takeuchi S, Tohyama K, Wakabayashi S. Method for removing asphalt pavement, system for removing asphalt pavement, electromagnetic induction coil unit, device for removing asphalt pavement, and method for stripping asphalt pavement. EP2003248 A2, 2008 .

[31] García A, Schlangen E, Van de Ven M, Liu Q. A simple model to define induction heating in asphalt mastic. Constr Build Mater 2012; 31: 38-46.

[32] Rudolf R, Mitschang P, Neitze M. Induction heating of continuous carbon-fibre reinforced thermoplastics. Composites Part A, Appl Sci Manuf 2000; 31: 1191-202.

[33] Metaxas AC. Foundations of electro-heat: A unified approach. New York: John Wiley and Sons 1996.

[34] Ahmed TJ, Stavrov D, Bersee HEN, Beukers A. Induction welding of thermoplastic composites-an overview. Composites Part A, App. Sci Manuf 2006; 37: 1638-51.

[35] Brown EN, Kessler MR, Sottos NR, White SR. In situ poly(ureaformaldehyde) microencapsulation of dicyclopentadiene. J Microencapsulation 2003; 20: 719-30.

[36] Salaün F. In Mittal V. Ed. Encapsulation nanotechnology. Massachussets: Scrivener Publishing LLC 2013: pp 137-74.

[37] Qiu J, Wu SP, Yu JY, Molenaar AAA. Investigating self-healing behaviour of pure bitumen using dynamic shear rheometer. Fuel 2011; 90: 2710-20

[38] Suryanarayana N V. Utilisation of electric power: Including electric drives and electric traction. $1^{\text {st }}$ Ed. New Delhi: New Age Inter-

[39] Koryu Ishii T. Handbook of microwave technology. California: Academic Press 1995

[40] Su JF, Schlangen E. Synthesis and physicochemical properties of high compact microcapsules containing rejuvenator applied in asphalt. Chem Eng J 2012; 198-199: 289-300.

[41] Su JF, Schlangen E, Qiu J. Design and construction of microcapsules containing rejuvenator for asphalt. Powder Technol 2013;235 563-71.

[42] Jeppson MR. Microwave method and apparatus for reprocessing pavements. US4319856A, 1982.

[43] Jeppson MR. Paving method and pavement construction for concentrating microwave heating within pavement material. US4594022A, 1986

[44] Long HW. Asphaltic compositions and uses therefor US6193793B1, 2001.

[45] Long HW. Method and apparatus for removing ice from paved surfaces. US4571860, 1986.

[46] Long HW, Long GE. Asphaltic compositions and uses therefor. US5441360A, 1995 .

[47] Hutcheson WR, Osborne TL. Asphalt compounds and method for asphalt reconditioning using microwave radiation. US4849020A, 1989.

[48] Bowen RF, Dudley KW, Sklenak JS. Tack compounds and microwave method for repairing voids in asphalt pavement US5092706A, 1992

[49] Liu Q, Schlangen E, García A, van de Ven M. Induction heating of electrically conductive porous asphalt concrete. Constr Build Mater 2010; 24: 1207-13.
[50] García A, Schlangen E, Van de Ven M, Liu Q. Electrical conductivity of asphalt mortar containing conductive fibers and fillers Constr Build Mater 2009; 23: 3175-81.

[51] Wen S, Chung DDL. Effects of carbon black on the thermal, mechanical and electrical properties of pitch-matrix composites. Carbon 2004; 42: 2393-7.

[52] Wu S, Mo L, Shui Z, Chen Z. Investigation of the conductivity of asphalt concrete containing conductive fillers. Carbon 2005; 43 : 1358-63.

[53] Wu S, Mo L, Shui Z. The development of recycling agent for asphalt pavement. J Wuhan Univ Technol 2002; 17: 63-5.

[54] Wu S, Liu X, Ye Q, Li N. Self-monitoring electrically conductive asphalt-based composite containing carbon fillers. T Nonferr Meta Soc 2006; 16: 512-6.

[55] Pang L, Tang X, Zhang J, Shi H, Han N. An inorganic nanomaterials modified asphalt and its preparation method. CN102408730A, 2012

[56] Goldin VV, Kondratev DN, Merkelene NF. Nanostructuring modifier for asphalt concrete based on carbon nanoparticles. RU2412126C1, 2009.

[57] Sun L, Guan H, Ge Q. Research on the performance of asphalt modified by SBS rubber and carbon nanotube. Appl Mech Mater 2011; 99-100: 1243-46.

[58] Ghasemia M, Marandia SM, Tahmooresib M, Kamalia RJ, Taherzadec R. Modification of stone matrix asphalt with nano-SiO2. J Basic Appl Sci Res 2012; 2:1338-44.

[59] Hao XH, Zhang A, Yang W. Study on the performance of nano calcium carbonate modified asphalt concrete AC-13. Adv Mater Res 2012; 450-451: 503-7.

[60] Yu. JY, Zeng X, Wu SP, Wang L, Liu G. Preparation and properties of montmorillonite modified asphalt. Mater Sci Eng A 2007; 447: 233-8.

[61] Ghile DB. Effects of nanoclay modification on rheology of bitumen and on performance of asphalt mixtures. Msc thesis, Delft Univer-sity of Technology, Delft, The Netherlands, June 2006.

[62] Tanzadeh J, Vahedi F, Kheiry P, Tanzadeh R. Laboratory study on the effect of nano-TiO2 on rutting performance of asphalt pavements. Adv Mater Res 2012; 622-623: 990-4

[63] Shafabakhsh G, Mirabdolazimi SM, Sadeghnejad M. Evaluation the effect of nano-TiO2 on the rutting and fatigue behavior of as-phalt mixtures. Constr Build Mater 2014; 54: 566-71.

[64] Qiu J, Van der Ven MFC, Wu S, Yu J, Molenaar AAA. Investigation the self healing capacity of bituminous binders. Road Mater Pavement Des 2009; 10: 81-94.

[65] Varley RJ, Zwaag S. An investigation of the self-healing mechanism of ionomer based system. Proceedings of the First Interna-tional Conference on Self-Healing Materials. Noordwijk aan Zee, The Netherlands, April 18-20, 2007.

[66] Luc M, Pagnini D, Torti L. Modified bitumen usable within a wide temperature range, and process for preparing it. EP0548412 A1, 1993.

[67] Dane C, David L. Alpha olefin-a,b-ethylenically unsaturated carboxylic acid copolymer or ionomer. US4839404 A, 1989.

[68] Shi Y. High temperature shape memory polymers \& ionomer modified asphalts. PhD Thesis, University of Akron, Ohio, USA, August 2013 